\title{
Corrosion Behavior and Mechanism of Irradiated 304 Nuclear Grade Stainless Steel in High-Temperature Water
}

\author{
Ping Deng ${ }^{1,2} \cdot$ En-Hou Han ${ }^{1} \cdot$ Qunjia Peng ${ }^{1,3} \cdot$ Chen Sun $^{4}$
}

Received: 7 January 2020 / Revised: 21 June 2020 / Accepted: 30 June 2020 / Published online: 18 August 2020

(c) The Chinese Society for Metals (CSM) and Springer-Verlag GmbH Germany, part of Springer Nature 2020

\begin{abstract}
Corrosion behavior and mechanism of irradiated 304 nuclear grade stainless steel were studied in simulated pressurized water reactor primary water. The microstructure of the oxide formed on the steel irradiated to different doses over an exposure period range of 25-1500 h was analyzed and compared. It was found that the general and intergranular corrosion rates of the steel were increased with irradiation dose, in correspondence with an evolution of the general oxide and the oxide formed at the grain boundary. Correlation of the oxide evolution with the corrosion kinetics and mechanism has been discussed in detail.
\end{abstract}

Keywords Stainless steel $\cdot$ Irradiation $\cdot$ High-temperature corrosion $\cdot$ Intergranular corrosion

\section{Introduction}

The austenitic stainless steel is traditionally used for fabrication of core components of the pressurized water reactors (PWRs) due to its high corrosion resistance and excellent mechanical property. However, it was found that the steel was susceptible to irradiation-assisted stress corrosion cracking (IASCC) in the primary PWR water [1-4]. To date, a number of studies on the IASCC have been reported. Studies showed that the radiation-induced microstructure is one of the key factors leading to IASCC of the steel [5-15]. Irradiation produces high density of defect clusters such as dislocation loops and cavities in the steels. These defect clusters act as obstacles for dislocation motion, leading to a change from a homogenous deformation mode to a highly heterogeneous deformation mode. Such a change in deformation mode

Available online at http://link.springer.com/journal/40195.

En-Hou Han

ehhan@imr.ac.cn

1 CAS Key Laboratory of Nuclear Materials and Safety Assessment, Institute of Metal Research, Chinese Academy of Sciences, Shenyang 110016, China

2 Nuclear Power Institute of China, Chengdu 610213, China

3 Suzhou Nuclear Power Research Institute, Suzhou 215004, China

4 State Power Investment Corporation Research Institute, Beijing 102209, China promoted localized deformation with strain accumulation and inhomogeneous strain distribution adjacent to the grain boundaries, which accelerated the initiation and coalescence of intergranular cracks. The localized deformation, on the other hand, also promoted dislocation channeling in the substrate by dislocation glide. As a result, the deformation was localized into the dislocation channel, which could also be a potential factor leading to IASCC by promoting dislocation pileups at the grain boundary region $[5-7,16]$. These investigations indicated that the promoted localized deformation and the dislocation channeling were key factors promoting the IASCC.

Despite the extensive database, the mechanism of IASCC was still incompletely understood. Previous studies related to the irradiation effect on IASCC were mainly focused on the microstructure and mechanical property changes induced by irradiation. As a principal form of stress corrosion cracking (SCC), IASCC is caused by the combination of a susceptible material, a corrosive environment and an applied stress. This indicated that corrosion is another key factor affecting the IASCC $[17,18]$. To fully clarify the effect of irradiation on SCC, a better understanding of irradiation effect on corrosion is needed. Further, in order to understand the irradiation effect on corrosion, it firstly needs to know whether the irradiation affects the corrosion, especially for the general corrosion and the intergranular corrosion. Secondly, it needs to know the kinetics of the irradiation affecting corrosion. The first stage for correlating the irradiation with corrosion has been done in one of our previous studies combined with 
the studies by Perrin et al. [19-22]. It was found that irradiation promoted both the general and intergranular corrosions of austenitic stainless steel in high-temperature water, which was primarily due to the radiation-induced defects and segregation at the grain boundary. To date, the second stage for correlating the irradiation with corrosion kinetics has still remained unknown, in particular to the correlation of the oxide evolution with irradiation dose at early and longer corrosion stage.

This study updates the previous paper with the corrosion kinetics data of proton-irradiated 304 nuclear grade stainless steel in primary PWR water. The objectives are to clarify the evolution of oxide microstructure in light of the corrosion mechanisms. The steel subjected to several levels of irradiation doses was exposure to the simulated PWR primary water over an exposure period range of 25 to $1500 \mathrm{~h}$. Following the exposure tests, microstructure of the oxide scale was characterized using scanning electron microscopy (SEM), X-ray photoelectron spectroscopy (XPS) and transmission electron microscope (TEM).

\section{Experimental}

\subsection{Specimens and Proton Irradiation}

The material, specimen preparation techniques and proton irradiation were described in detail in a previous study [19] and will be summarized here briefly. The material used for the experiment was solution-annealed (SA) 304 nuclear grade stainless steel, and the chemical composition is listed in Table 1. Specimens were cut from the steel to a dimension of $20 \mathrm{~mm} \times 3 \mathrm{~mm} \times 2 \mathrm{~mm}$ by using electrical discharge machining. The specimens were at first mechanically ground with $\mathrm{SiC}$ abrasive papers up to 3000 grit and then polished by diamond pastes of $1 \mu \mathrm{m}$. At last, the specimens were further exposed to colloidal silica slurry polishing for $\sim 2 \mathrm{~h}$ before proton irradiation. This final colloidal silica slurry polishing effectively ensured the removal of the mechanical damage produced during earlier grinding and polishing steps, which was determined by the surface examination using high-resolution SEM and electron backscatter diffraction (EBSD).

The specimens were irradiated with $2 \mathrm{meV}$ protons using a General Ionex Tandetron Accelerator at the Ion Beam Laboratory at the University of Michigan, to doses of $0.5,1.5$ and 3 displacements per atom (dpa), respectively. The dose rate as calculated by the computer code of Stopping and Range of Ions in Materials 2008 (SRIM 2008 ) was $\sim 5.96 \times 10^{-6}$ dpa per second $\left(\mathrm{dpa} \mathrm{s}^{-1}\right)$. The irradiation temperature was controlled at $360{ }^{\circ} \mathrm{C}$ and monitored by a two-dimensional thermal imager that could keep the target temperature variation within $\pm 10{ }^{\circ} \mathrm{C}$ by adjusting the heating and cooling provided to the back of the specimen stage. The $2 \mathrm{MeV}$ protons created a $20-\mu \mathrm{m}$-thick damaged layer with a nearly uniform damage profile within the $\sim 1$ to $\sim 10 \mu \mathrm{m}$. The implantation peak was at $\sim 18 \mu \mathrm{m}$ of the irradiation damage profile. Previous analysis showed that the radiation-induced damage was mainly dislocation loops with a few micro-voids. The size and density of dislocation loops were both increased with increasing irradiation dose and tended to saturate at 3-5 dpa with an average size of $6-10 \mathrm{~nm}$ and a number density of approximately $10^{22} \mathrm{~m}^{-3}$. The $\mathrm{Cr}$ depletion by radiation-induced segregation (RIS) at grain boundary was $3.5 \pm 0.9$ at $\%$ following the 0.5 dpa irradiation, which increased to $5.4 \pm 0.5$ at $\%$ by the 1.5 dpa irradiation and further to $9.2 \pm 0.9$ at $\%$ by the irradiation dose of 3-5 dpa [19, 23]. The C, S, and P showed no segregation at the grain boundary after the irradiation.

\subsection{Corrosion Test}

After the proton irradiation, the specimens were polished again using the colloidal silica slurry for half an hour. This was done to obtain fresh surfaces by removing the surface with a thickness of 1-2 $\mu \mathrm{m}$. As a result, surfaces of the specimens across different doses were consistent for the subsequent corrosion test. Corrosion test was performed at $320^{\circ} \mathrm{C}$ and $13 \mathrm{MPa}$ in a 3-L autoclave made of 316 L stainless steel. The autoclave equipped with a $90-100 \mathrm{~mL} \mathrm{~min}^{-1}$ refreshed water loop capable of simulating primary PWR water. The water flow and pressure were maintained by a high-pressure pump connected with a backpressure valve, while the temperature in the autoclave was achieved by one preheater at the autoclave inlet and two resistance heating bands at the autoclave surface, which were controlled by the k-type thermocouple with an accuracy of $\pm 1{ }^{\circ} \mathrm{C}$. The primary water was obtained by mixing deionized water with $1200 \mathrm{mg} \mathrm{L}^{-1}$ of $\mathrm{B}$ as $\mathrm{H}_{3} \mathrm{BO}_{3}$ and $2.3 \mathrm{mg} \mathrm{L}{ }^{-1}$ of $\mathrm{Li}$ as $\mathrm{LiOH} \cdot \mathrm{H}_{2} \mathrm{O}$. After the chemicals were added into the water tank, the water was deoxygenated to $\leq 5 \mu \mathrm{g} \mathrm{L}^{-1}$ dissolved oxygen by bubbling $\mathrm{H}_{2}$ gas into the water tank, followed by storing $\mathrm{H}_{2}$ in the tank in equilibrium with a $0.08 \mathrm{MPa}$ hydrogen overpressure. This overpressure resulted in a dissolved hydrogen of $2.6 \mathrm{mg} \mathrm{L}^{-1}$ in the water. For the experiments of a long exposure period $(>500 \mathrm{~h})$, the hydrogen in the water tank
Table 1 Chemical composition (wt $\%$ ) of 304NG stainless steel

\begin{tabular}{lllllllll}
\hline $\mathrm{C}$ & $\mathrm{Mn}$ & $\mathrm{Si}$ & $\mathrm{S}$ & $\mathrm{P}$ & $\mathrm{Ni}$ & $\mathrm{Cr}$ & $\mathrm{Co}$ & $\mathrm{Fe}$ \\
\hline 0.04 & 1.73 & 0.27 & 0.002 & 0.021 & 8.87 & 19.51 & 0.04 & $\mathrm{Bal}$ \\
\hline
\end{tabular}


was refreshed every $500 \mathrm{~h}$ to ensure the reactivity. Dissolved hydrogen (DO), dissolved oxygen (DH) and conductivity of the water were continuously monitored during the tests. To determine the time dependence of oxide microstructure evolution, a set of exposures was conducted with a constant period of 25, 100, 500, 1000 and $1500 \mathrm{~h}$. For all exposures, the heating and cooling process of the autoclave was finished within $2-3 \mathrm{~h}$ to reduce the effect of temperature change.

\subsection{Characterization of the Oxide Formed in Primary Water}

To study the corrosion behavior, the oxide formed on the specimens in the primary water following different exposure times was characterized by several techniques (SEM, XPS and TEM).

A FEI XL30 Field Emission Gun SEM (FEG-SEM) was at first used to examine the surface morphology of the oxide scale, followed by characterizing the depth profile of the oxide scale in an ESCALAB 250 XPS system by sequential sputtering of the oxides. The sputtering was conducted by using a $2 \mathrm{keV}$ argon ion beam rastering an area of $2 \mathrm{~mm}$ diameter at a rate of $0.1 \mathrm{~nm} \mathrm{~s}^{-1}$. The large survey spectrum and chemical states of $\mathrm{Cr}, \mathrm{Ni}, \mathrm{Fe}$ and $\mathrm{O}$ were systematically recorded. The depth profile at which the $\mathrm{O}$ content was half that of the surface was used to determine the average thickness of oxide. On the other hand, the morphology and thickness of the oxide were observed and measured in a cross section in a TEM (JEM-2100). The TEM was equipped with a Gatan 4k CCD camera for capturing high-resolution TEM images and an energy-dispersive X-ray spectroscopy (EDX) device for composition analysis. The high-resolution TEM images were used for identifying the oxides in the grains and at the grain boundaries and further used for measuring the oxide thickness. Both the point and mapping EDX analyses were used to highlight the local composition variations in the oxides.

TEM samples of cross sections were prepared by a FEI Quanta 200 3D focus ion beam (FIB) system using the traditional lift-out techniques, which ensured the precise sampling of the cross section of the oxide scale containing a selected grain boundary. The specimens with irradiation doses of 0.5 and 1.5 dpa following the 25-, 100-, 500-, 1000and 1500-h exposure were selected for the TEM analysis. A total of about 30 data points were obtained for each of the two irradiated specimens after each exposure time. Note that the type of grain boundaries would affect the corrosion behavior; thus, only the random high-angle grain boundaries were of interest to select for TEM sample preparation, while the small-angle and twin grain boundaries were avoided by using ion channeling contrast of the grains [24]. This further aided in the solid comparison of the depth of the oxide formed at the grain boundaries. Once a grain boundary was selected, platinum was at first used to coat the surface of the specimen to identify the location and avoid ion beam damage. Then, sample wedges were cut from the selected grain boundary and were thinned to a thickness of $\sim 80 \mathrm{~nm}$ in the FIB system with a Ga beam using voltages of 30,20 and $10 \mathrm{keV}$ and current ranging from $7 \mathrm{nA}$ to $30 \mathrm{pA}$.

\section{Results}

\subsection{Surface Morphology Observed by SEM}

SEM observations of the oxide scale formed on the SA and irradiated specimens following the exposures in the primary water with various exposure periods are shown in Fig. 1. The exposure resulted in formation of a similar duplex layer oxide scale with an outer layer of polyhedral oxide particles and an inner layer of continuous oxide film on the SA and irradiated specimens. Both the number and size of the oxide particles formed at a higher irradiation dose were found to be larger in the exposure period of $25-500 \mathrm{~h}$. Further, at the exposure period of $1000 \mathrm{~h}$, the oxide particles on SA and 0.5 dpa irradiated specimens showed a smaller size, while few changes were pointed out on the 1.5 and 3 dpa specimens until increasing the exposure period to $1500 \mathrm{~h}$. This suggested an evolution of the oxide in accordance with the irradiation dose.

\subsection{Depth Profile Analyzed by XPS}

Figure $2 \mathrm{a}-\mathrm{h}$ shows the depth profiles of the oxide scales formed on the 0.5 and 1.5 dpa irradiated specimens after the exposure for 500, 1000 and $1500 \mathrm{~h}$. Concentrations of $\mathrm{Cr}$, $\mathrm{Ni}$ and $\mathrm{Fe}$ shown in the figures were normalized to the total concentration of them, so that the influence of oxygen on the depth profile was excluded. The oxide scale equivalent thickness shown in the figures was assessed by the half-height of oxygen and is summarized in Fig. 3. As illustrated, while the oxide scales grew with exposure period of $\leq 500 \mathrm{~h}$, a transition of the oxide thickness occurred after the 1000-h exposure for the SA and 0.5 dpa irradiated specimens. By increasing the exposure period further to $1500 \mathrm{~h}$, a similar transition was also observed on the 1.5 and 3 dpa specimens, which was in agreement with the SEM observations.

\subsection{Depth Profile Analyzed by TEM}

\subsubsection{General Corrosion Behavior}

Figure 4 shows the depth profile of the oxide scale formed on 1.5 dpa irradiated specimens after the 100- and 1000-h exposures. It revealed a similar oxide structure following the 100- and 1000-h exposure, i.e., the inner continuous oxide 


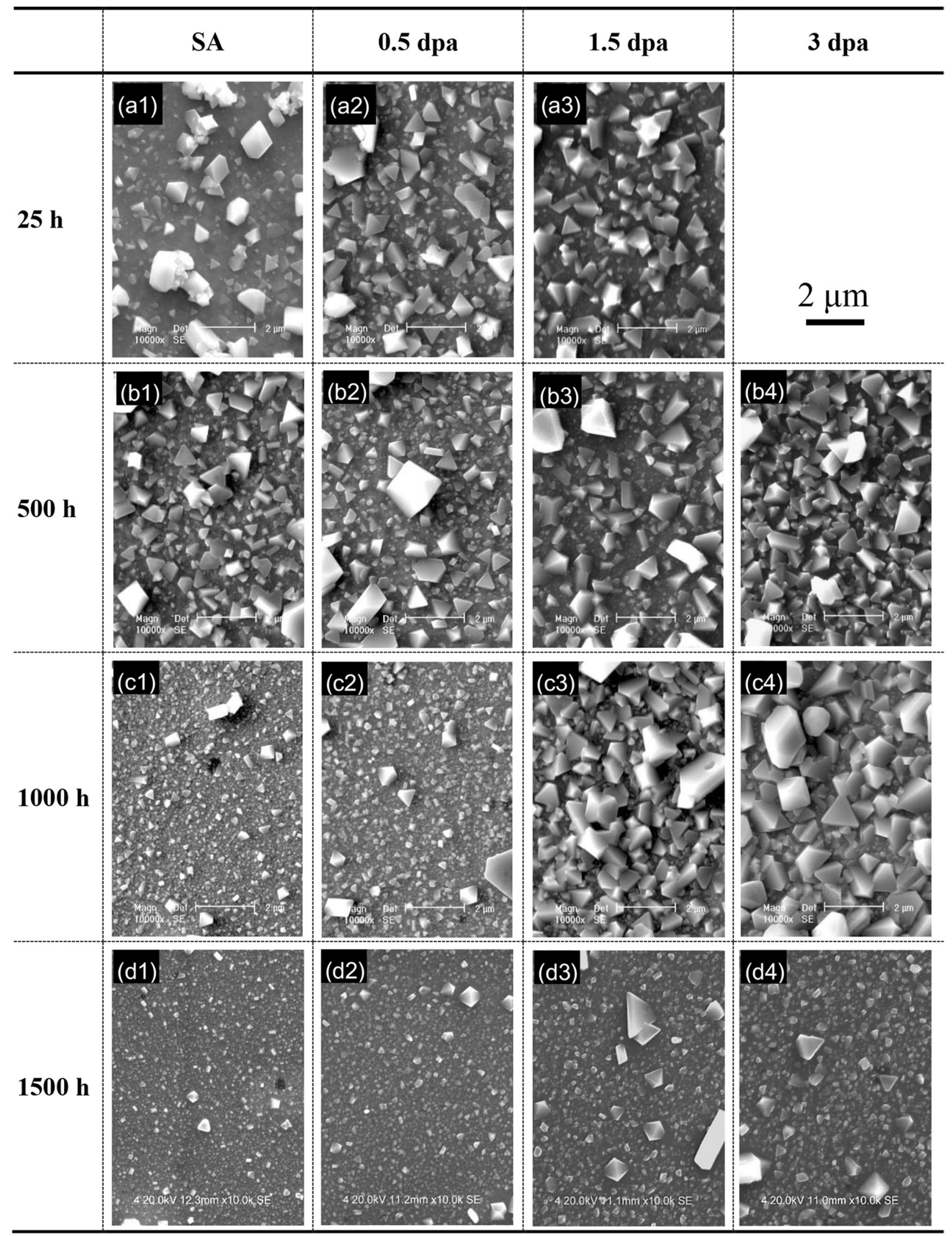


४Fig. 1 Surface morphologies of the oxide scales formed on solutionannealed a1, b1, c1, d1, 0.5 dpa a2, b2, c2, d2, 1.5 dpa a3, b3, c3, d3 and 3 dpa b4, c4, d4 irradiated specimens following the exposure in simulated primary PWR water at $320^{\circ} \mathrm{C}$ for the period of $25 \mathrm{~h} \mathrm{a1}$, a2, a3, $500 \mathrm{~h}$ b1, b2, b3, b4, $1000 \mathrm{~h}$ c1, c2, c3, c4 and $1500 \mathrm{~h} \mathrm{d1,} \mathrm{d2,}$ d3, d4

film and oxide particles on it. This is in consistence with the previous studies [19-21]. High-resolution TEM observations and electron diffraction shown in Fig. 4c and d indicated that the continuous oxide films formed after the 100- and 1000-h exposure had a similar crystalline structure of spinel. The EDX line scans revealed that the inner continuous oxide film mainly consisted of $\mathrm{Fe}, \mathrm{Ni}$ and $\mathrm{Cr}$ oxide, suggesting that it was $\mathrm{Fe}-\mathrm{Cr}-\mathrm{Ni}$ spinel. Further, no variation in $\mathrm{Cr}$ content of the inner continuous oxide after the 100- and 1000-h exposures was found.

Nevertheless, further observation also displayed a difference in the thickness of the inner continuous oxide film. As shown in Fig. 4a and b, the inner continuous oxide film formed following a longer exposure time was thicker. The thickness of the inner continuous oxide film was used to determine the oxidation rate. Figure 5 presents the time dependence of the oxidation rate at 0.5 and $1.5 \mathrm{dpa}$. The results showed the oxidation rate followed the power law:

$D=k_{\mathrm{D}} t^{n}$

where $D$ is the thickness of the inner continuous oxide, $k_{D}$ is the oxidation constant, $t$ is the exposure time in hour and $n$ is the time exponent on thickness.

As illustrated, the thickness fit to the power law resulted in a similar time exponent for the 0.5 - and 1.5 dpa irradiated specimens, suggesting that the oxidation mechanism was similar [25]. While the time exponent was similar, the oxidation rate constant was larger for a higher irradiation dose, which suggested a higher diffusion rate of species in the inner continuous oxide.

\subsubsection{Intergranular Corrosion Behavior}

Figures 6, 7, 8, 9, 10 show the TEM observation and analysis of the intergranular oxide formed on 0.5 and $1.5 \mathrm{dpa}$ specimens after the 25-, 100- and 1500-h exposures. After the 25-h exposure, the oxide formed at the grain boundary on both specimens was found to be flat, implying no further oxidation along the grain boundary, as displayed by the EDX mappings of Fe, $\mathrm{Cr}$, Ni and $\mathrm{O}$ in Fig. 6c and d. Nevertheless, increasing the exposure to a longer period of $100 \mathrm{~h}$, the oxide formed at the grain boundary was found to be a concave morphology (Figs. 7a and 8a). This suggested a nature of intergranular corrosion. Further, the oxidation penetration into grain boundary on $1.5 \mathrm{dpa}$ irradiated specimen was larger than that on $0.5 \mathrm{dpa}$ irradiated specimen, suggesting a higher intergranular corrosion rate at $1.5 \mathrm{dpa}$. As shown in Figs. 7a and 8a, the oxide depth at $1.5 \mathrm{dpa}$ was about $50 \mathrm{~nm}$, while it was $\sim 30 \mathrm{~nm}$ at $0.5 \mathrm{dpa}$.

Increasing the exposure period further to $1500 \mathrm{~h}$, the depth of oxidation penetration into the grain boundary on 0.5 dpa irradiated specimen grew to $190 \mathrm{~nm}$ (Fig. 9a). On the other hand, the intergranular oxide formed on $1.5 \mathrm{dpa}$ irradiated specimen grew further to a penetration depth of $\sim 240 \mathrm{~nm}$, as shown in Fig. 10a.

EDX mappings and line scans shown in Figs. 7, 8, 9, 10 displayed the composition evolution of the intergranular oxide formed on 0.5 and $1.5 \mathrm{dpa}$ irradiated specimens following the 100- and 1500-h exposures. After the 100-h exposure, a similar oxygen level ( 40 at $\%)$ was found in the both intergranular oxides, while the Ni content showed difference. The Ni content in intergranular oxide showed a slight depletion on the $1.5 \mathrm{dpa}$ irradiated specimen, while no such depletion was observed on the 0.5 dpa irradiated specimen, as shown in Figs. 7c and 8c. After the 1500-h exposure, the oxygen content in both intergranular oxides reached a value of approximately 50 at $\%$, leading to more oxidation of $\mathrm{Cr}$ and $\mathrm{Fe}$, as displayed by the composition profiles shown in Figs. 9c and 10c. The $\mathrm{Cr}$ content on $0.5 \mathrm{dpa}$ irradiated specimen increased to a concentration of $\sim 69.0$ at $\%$, which was approximately 12 at $\%$ higher than that on the 1.5 dpa irradiated specimen (56.9 at\%). Further, Ni was found almost fully depleted in intergranular oxides on both 0.5 and 1.5 dpa irradiated specimens. This suggested that the composition of intergranular oxide developed as the oxidation advanced.

EDX line scans shown in Figs. 7d, 9d, 10d displayed the evolution of the composition adjacent to the intergranular oxide. The EDX profiles were conducted across the grain boundary beneath the intergranular oxide with a distance of about $20 \mathrm{~nm}$. Following 100-h exposure, a localized Nienrichment region was observed ahead the tip of the intergranular oxide on 1.5 dpa irradiated specimen, while the same zone ahead the oxide tip on 0.5 dpa irradiated specimen was free of oxygen attack but only showed a Cr depletion and a Ni enrichment by RIS. This indicated that the oxidation did not stop at the interface between oxide and metal but easily progressed along the grain boundary and enabled by a higher irradiation dose. Following 1500-h exposure, a similar nature of Ni enrichment was observed on both specimens, while Ni concentration on 0.5 dpa irradiated specimen was approximately 15 at $\%$ higher than that on the $1.5 \mathrm{dpa}$ irradiated specimen (Figs. 9a and 10a).

The TEM results shown in Figs. 6, 7, 8, 9, 10 suggested a difference in intergranular corrosion rate on the 0.5 and 1.5 dpa irradiated specimens. The difference in intergranular corrosion rate is in correspondence with a different oxide formed at the grain boundary. 


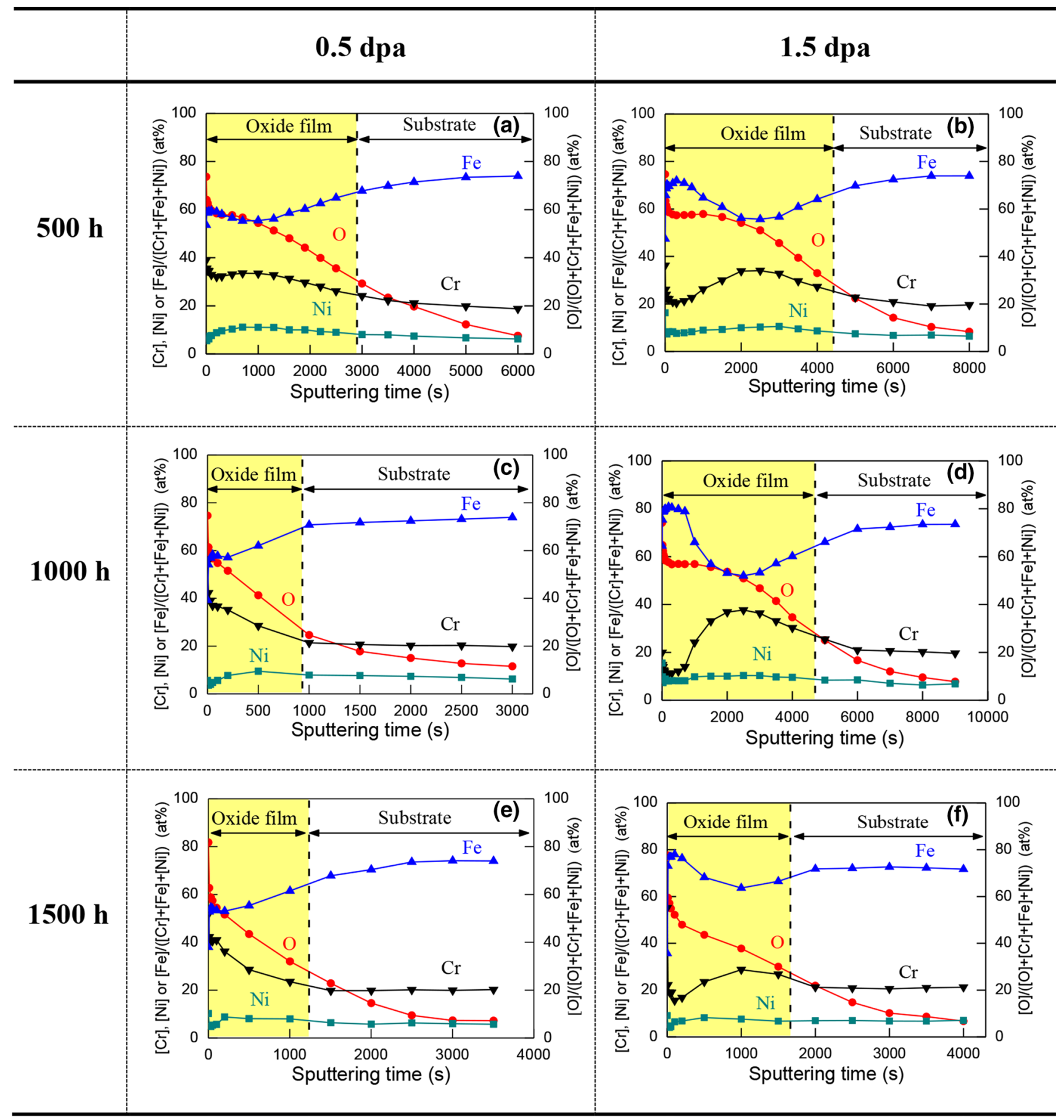

Fig. 2 XPS composition profiles of the oxide scales formed on 0.5 and 1.5 dpa irradiated specimens following the exposure for $500 \mathrm{~h}$ a, b, $1000 \mathrm{~h} \mathrm{c}, \mathbf{d}$ and $1500 \mathrm{~h} \mathbf{e}, \mathbf{f}$. The black vertical lines located at half of the highest $\mathrm{O}$ concentration display the thickness of the oxide film

\section{Discussion}

\subsection{Effect of Irradiation on Evolution of General Corrosion}

The previous observation and analyses revealed that large oxide particles with a lower packing density were formed in a short exposure time of $\leq 500 \mathrm{~h}$, while small oxide particles with a higher packing density were formed by increasing the exposure period to 1000-1500 h. Further, an increase in thickness of the inner oxide with increasing irradiation dose was confirmed. These results indicated that the general corrosion rate of the steel in PWR primary water was increased by a higher irradiation dose. This was 


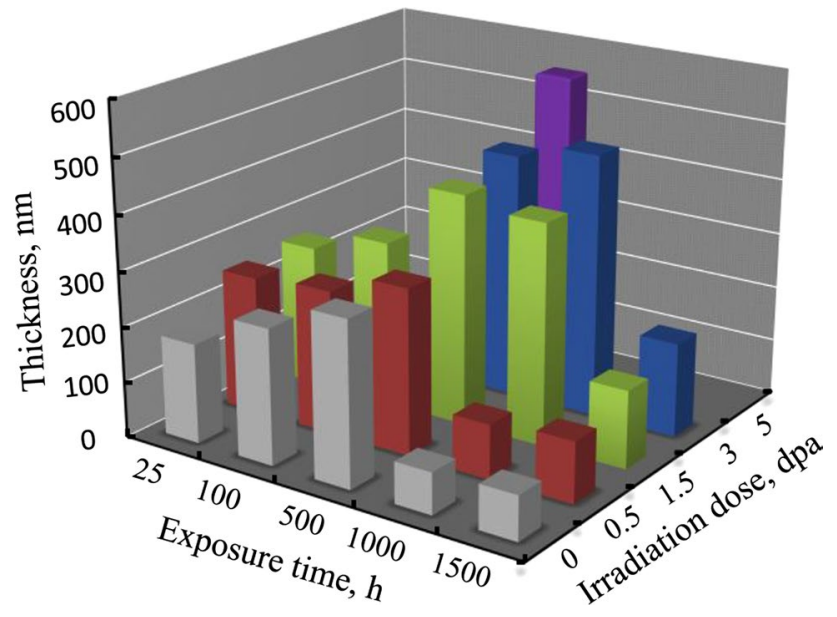

Fig. 3 Thickness of the oxide scales on 304 NG SS as a function of irradiation dose and exposure time accompanied with an evolution of the size and density of oxide particles.

According to the SEM and TEM results shown in Figs. 1 and 4 , thickness of the outer layer with the oxide particles is much larger than that of the inner oxide film. As such, the total oxide scale thickness was most likely believed to depend on the size and density of the oxide particles in the outer layer. Further, as reported, formation and growth of oxide particles were determined by the Fe ions diffusion rates in the inner oxide by solid-state mechanism and dissolution rate of the oxide particles in the outer layer by dissolution-precipitation mechanism [26-30]. The DH in the primary water created a low potential at the oxide/water interface, resulting in the dissolution of ions into the primary water [31]. At the short exposure periods of $\leq 500 \mathrm{~h}$, the inner oxide was relatively thinner. Fe ions could easily diffuse through the inner oxide, which promoted the formation and growth of the oxide particles. As a result, the density and size of oxide particles in the outer layer were found to be larger. Further, as acknowledged by literature [19, 20], increasing the irradiation dose would provide more sites of preferential oxidation, resulting in more nucleation of the

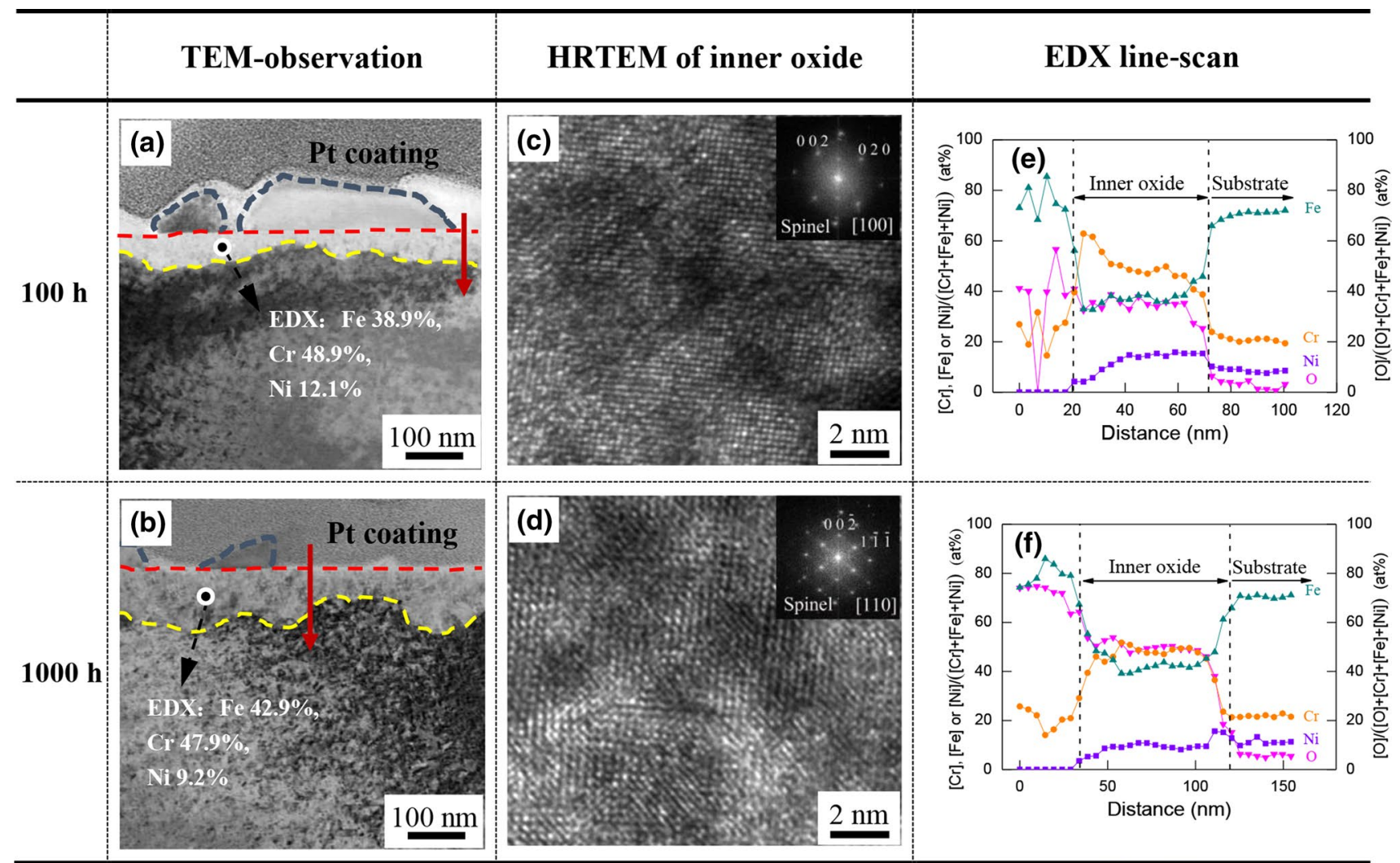

Fig. 4 TEM observation and analysis of the cross section of the oxide scales formed on $1.5 \mathrm{dpa}$ irradiated specimens of 304NG SS following the 100- and 1000-h exposure in simulated primary PWR water. a and b TEM observations of the cross section of the oxide scales. $\mathbf{c}$ and $\mathbf{d}$ highresolution observations and analysis of the inner oxide. $\mathbf{e}$ and $\mathbf{f}$ corresponding point scans collected along the red lines shown in $\mathbf{a}$ and $\mathbf{b}$, respectively 


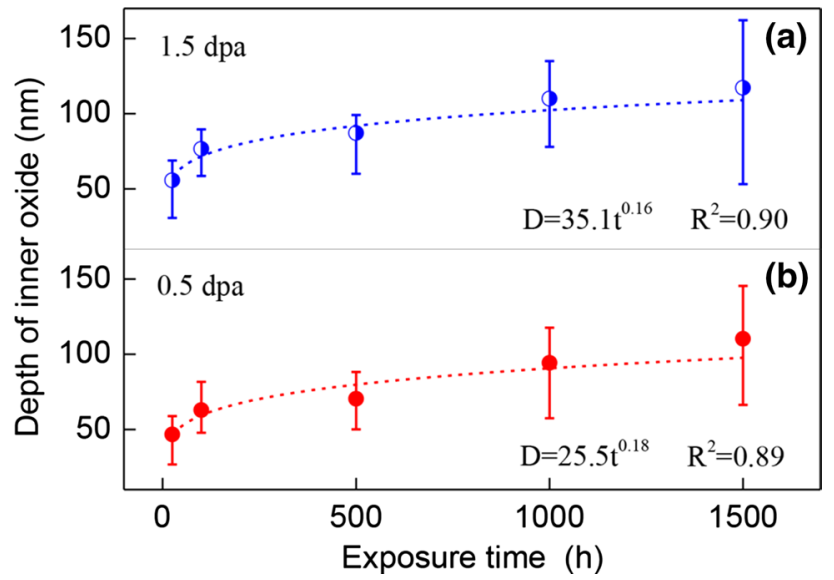

Fig. 5 Time-dependent inner oxide thickness obtained on 0.5 and 1.5 dpa irradiated specimens following the exposure to primary PWR water at $320{ }^{\circ} \mathrm{C}$. The experimental data were adjusted with a power fit, and the error bars mean the maximum and minimum values

oxide particles as well as a finer grain size of the inner oxide. According to Robertson oxidation model [32,33], the finer grain size of the inner oxide could provide more diffusion passes of grain boundaries, which promoted the diffusion of Fe ions. As such, the oxide particles' density and size were increased with increasing irradiation dose.

By increasing the exposure time to 1000 and $1500 \mathrm{~h}$, the inner oxide grew to be much thicker, as shown in Figs. 4 and 5. The larger thickness led to a decreased Fe ions diffusion rate in the inner oxide. Thus, the dissolution rate of the oxide particles in the outer layer is likely the key factor for the size and density change. Further, the dissolution rate of the oxide particles is dominated by the concentration of $\mathrm{Fe}$ and $\mathrm{Ni}$ ions at the oxide/water interface. The higher irradiation dose could certainly lead to a faster saturation of $\mathrm{Fe}$ and $\mathrm{Ni}$ ions at the interface between oxide and water, since the $\mathrm{Fe}$ and $\mathrm{Ni}$ ions' diffusion rate in the inner oxide formed at a higher irradiation dose was higher as indicated by the higher oxidation rate constant (Fig. 5). As a result, the dissolution process was mitigated. The difference in the dissolution process led to a different evolution of the oxide particles for the SA and irradiated specimens, as shown in Fig. 1. Further, the oxide particles on the irradiated specimens had a larger size (also shown in Fig. 1), which might be another reason for the different evolution since the dissolution time for the larger oxide particles is longer [20].

\subsection{Effect of Irradiation on Evolution of Localized Intergranular Corrosion}

The TEM results in Figs. 6, 7, 8, 9, 10 showed that increasing the irradiation dose and exposure time promoted intergranular corrosion of the steel in the PWR primary water. Further, increasing the irradiation dose and exposure time also led to difference in $\mathrm{Cr}$ content in the intergranular oxide, in addition to a localized Ni enrichment adjacent to the oxide. This indicated a correlation between the intergranular corrosion rate and the change in the intergranular oxide microstructure.

As acknowledged, increasing the irradiation dose could decrease the protectiveness of the inner oxide film [19]. Following the exposure to primary water, a thin and less protective inner oxide was expected to form on the specimen subjected to a higher irradiation dose (Fig. 6). The less protective nature of the inner oxide film allowed oxygen to penetrate and oxidize the underneath alloy more easily, leading to occurrence of intergranular corrosion (Figs. 7 and 8 ). As indicated by the Gibbs free energy-temperature $\left(\Delta G^{\circ}-T\right)$ map, the critical oxygen partial pressure required for formation of $\mathrm{Fe}, \mathrm{Cr}$, and $\mathrm{Ni}$ oxides is $\mathrm{Cr}<\mathrm{Fe}<\mathrm{Ni}$ [34, 35]. This indicated that the formation of $\mathrm{Cr}$ oxide was prior to the oxides of $\mathrm{Fe}$ and $\mathrm{Ni}$. When oxygen started diffuse in the grain boundary, $\mathrm{Cr}$ oxide was formed at first, while $\mathrm{Fe}$ ion diffused through the oxide and formed the oxide particle in the out layer, with $\mathrm{Ni}$ initially remaining static, as shown in Fig. 8. Due to the higher concentration of oxygen diffusing in the grain boundary on 1.5 dpa irradiated specimen, the preferential oxidation of $\mathrm{Cr}$ along the grain boundary could push $\mathrm{Ni}$ into the base metal by the growing $\mathrm{Cr}$ oxide [35-37]. This led to a Ni enrichment ahead of the intergranular oxide on $1.5 \mathrm{dpa}$ irradiated specimen after the 100-h exposure (Fig. 9). Further, simultaneously with the inward diffusion of oxygen, outward $\mathrm{Cr}$ diffusion occurred. As literature reported [38], the Cr diffusivity along grain boundary would also affect the Ni enrichment ahead of the intergranular oxide. The higher content of $\mathrm{Cr}$ at grain boundary on $1.5 \mathrm{dpa}$ irradiated specimen suggested a higher outward $\mathrm{Cr}$ diffusion. This might enhance the Ni enrichment adjacent to the oxide. According to the study by Kuang et al. [38], once the Ni enrichment reaches a certain concentration, diffusion-induced grain boundary would occur. In the following exposures with the periods of $>100 \mathrm{~h}$, inward diffusion of oxygen continued, as shown in Figs. 9c and 10c. As a result, the oxidation advanced, and more $\mathrm{Ni}$ was pushed into the base metal (Figs. 9d and 10d). Further, according to the composition analysis shown in Figs. 9c and 10c, the intergranular oxide on the $0.5 \mathrm{dpa}$ irradiated specimen had a higher $\mathrm{Cr}$ content than that on the $1.5 \mathrm{dpa}$ irradiated specimen. The higher content of $\mathrm{Cr}$ resulted from more $\mathrm{Cr}$ oxidation at the grain boundary, also leading to a larger Ni enrichment adjacent to the oxide, as shown in Figs. 9d and 10d.

The above discussion interrupted how the irradiation affected the microstructure of the intergranular oxide, as schematically shown in Fig. 11.

Difference in the intergranular oxide microstructure led to a different intergranular corrosion behavior. As reported, protectiveness of the oxide on austenitic alloys formed in 

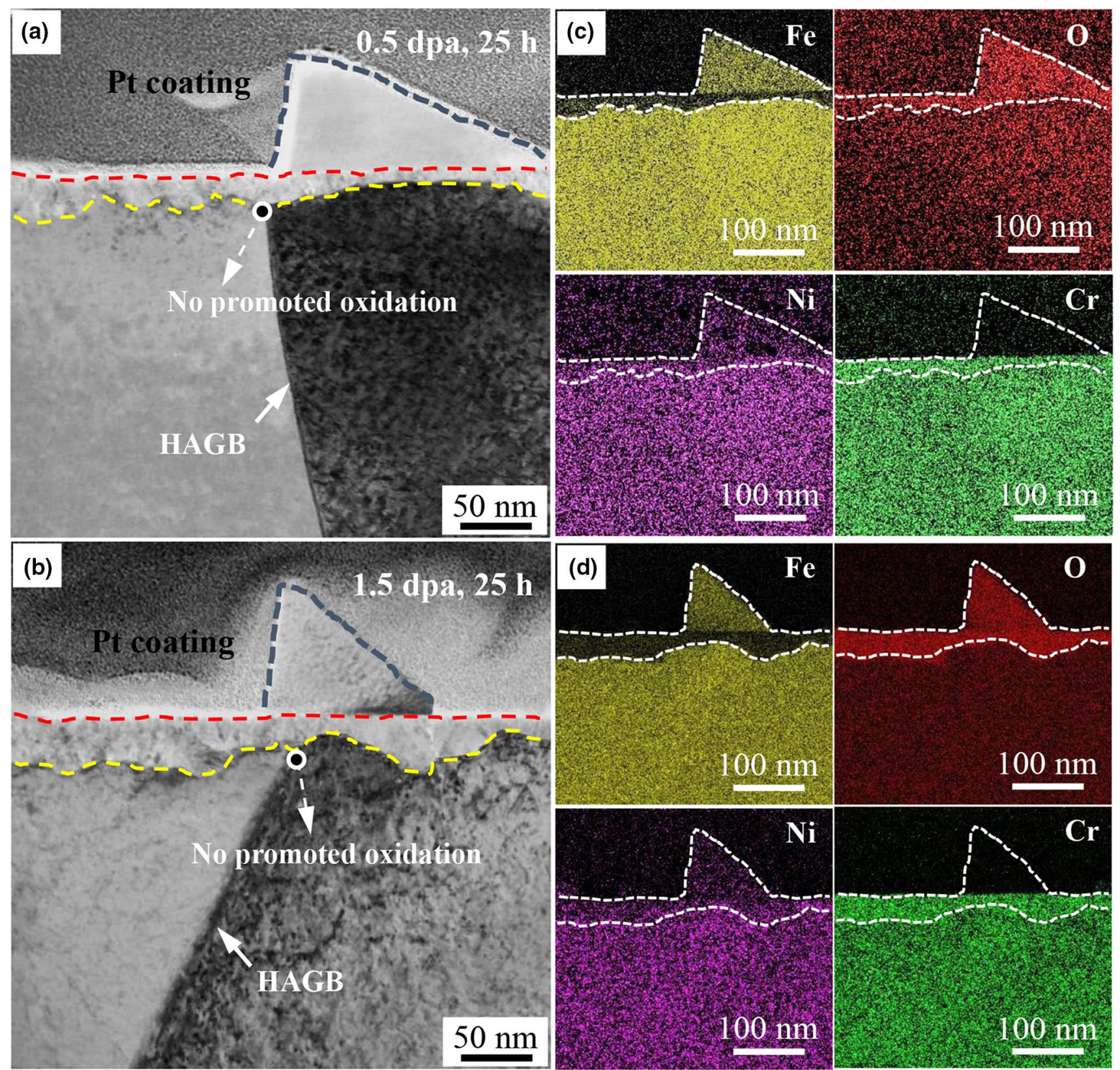

Fig. 6 a, b TEM observation of the cross section of a grain boundary on a 0.5 - and $\mathbf{b} 1.5$ dpa irradiated specimens following the 25-h exposure in primary PWR water at $320^{\circ} \mathrm{C}$. c, $\mathbf{d}$ The corresponding EDX mappings for $\mathrm{O}, \mathrm{Cr}, \mathrm{Fe}$ and $\mathrm{Ni}$, respectively

high-temperature water could be affected by the Cr content in oxide scale [26, 39-41]. As such, the different intergranular corrosion behavior in the 0.5 and 1.5 dpa irradiated specimens resulted from a joint effect of $\mathrm{Cr}$ content of the intergranular oxide and $\mathrm{Ni}$ enrichment adjacent to the oxide. More $\mathrm{Cr}$ in oxide indicated a higher protectability of the oxide, which could mitigate further oxidation by decreasing oxygen diffusion rate through the oxide itself. Difference in the Ni enrichment behavior also affected further oxidation along grain boundary by decreasing the diffusion of ions at the interface between oxide and matrix. On the basis of the point-defect mechanism, reactions of the oxide growth at the oxide/matrix interface were proposed [42]:

$2 \mathrm{Cr}_{\mathrm{Cr}}^{\times}+\mathrm{Fe}_{\mathrm{Fe}}^{\times} \leftrightarrow 2 \mathrm{Cr}_{\mathrm{Cr} \text { (oxide) }}^{\times}+\mathrm{Fe}_{\mathrm{Fe} \text { (oxide) }}^{\times}+4 \mathrm{~V}_{\mathrm{O} \text { (oxide) }}^{*}+8 \mathrm{e}^{-}$,

$\mathrm{M}+\mathrm{V}_{\mathrm{M}}^{\prime \prime} \leftrightarrow \mathrm{M}_{\mathrm{M}}^{\times}+2 \mathrm{e}^{-}$,

where the $\mathrm{Cr}_{\mathrm{Cr}}^{\times}$and $\mathrm{Fe}_{\mathrm{Fe}}^{\times}$are $\mathrm{Cr}$ and $\mathrm{Fe}$ cations in cation sites in the steel, $\mathrm{Cr}_{\mathrm{Cr} \text { (oxide) }}^{\times}$and $\mathrm{Fe}_{\mathrm{Fe} \text { (oxide) }}^{\times}$represent $\mathrm{Cr}$ and $\mathrm{Fe}$ ion lattice sites in the oxide, $\mathrm{V}_{\mathrm{O}}^{*}$ refers to oxygen ion vacancy in the oxide, $\mathrm{M}$ and $\mathrm{M}_{\mathrm{M}}^{\times}$refer to metal atom and metal cation in 

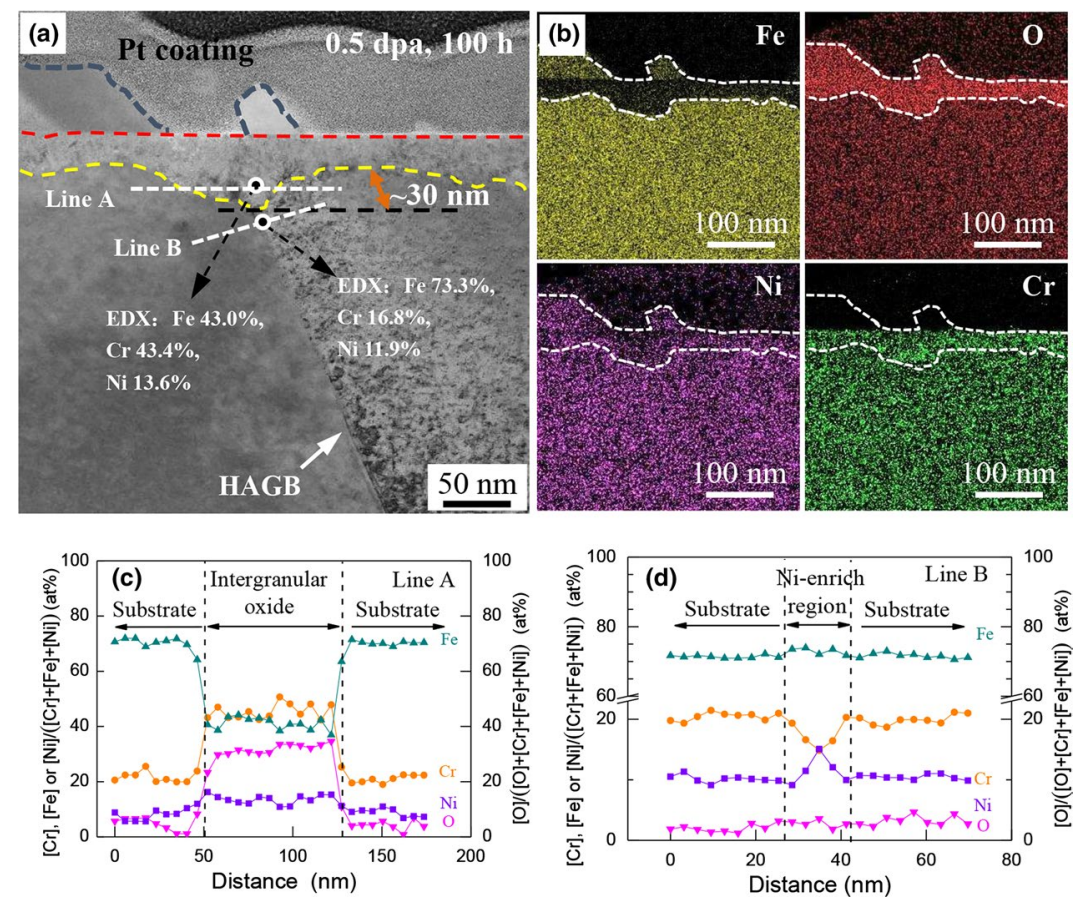

Fig. 7 a TEM observation of the cross section of a grain boundary on 0.5 dpa irradiated specimen following the 100-h exposure in PWR primary water at $320^{\circ} \mathrm{C}$. b The corresponding EDX mappings for O, Cr, Fe and Ni, respectively. $\mathbf{c}$ and $\mathbf{d}$ EDX point scans across the grain boundary collected along the red lines shown in a
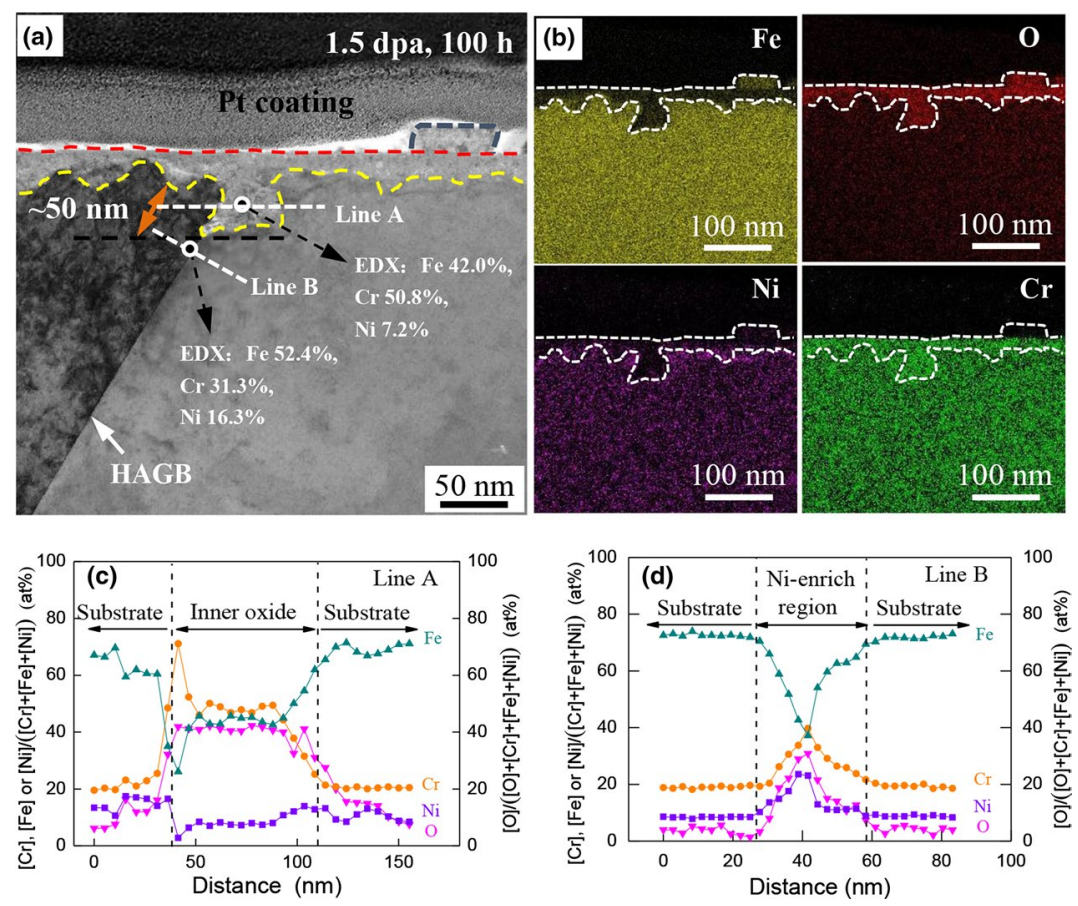

Fig. 8 a TEM observation of the cross section of a grain boundary on 1.5 dpa irradiated specimen following the 100-h exposure in PWR primary water at $320^{\circ} \mathrm{C}$. b The corresponding EDX mappings for $\mathrm{O}, \mathrm{Cr}, \mathrm{Fe}$ and $\mathrm{Ni}$, respectively. $\mathbf{c}$ and $\mathbf{d}$ EDX point scans across the grain boundary collected along the red lines shown in a 

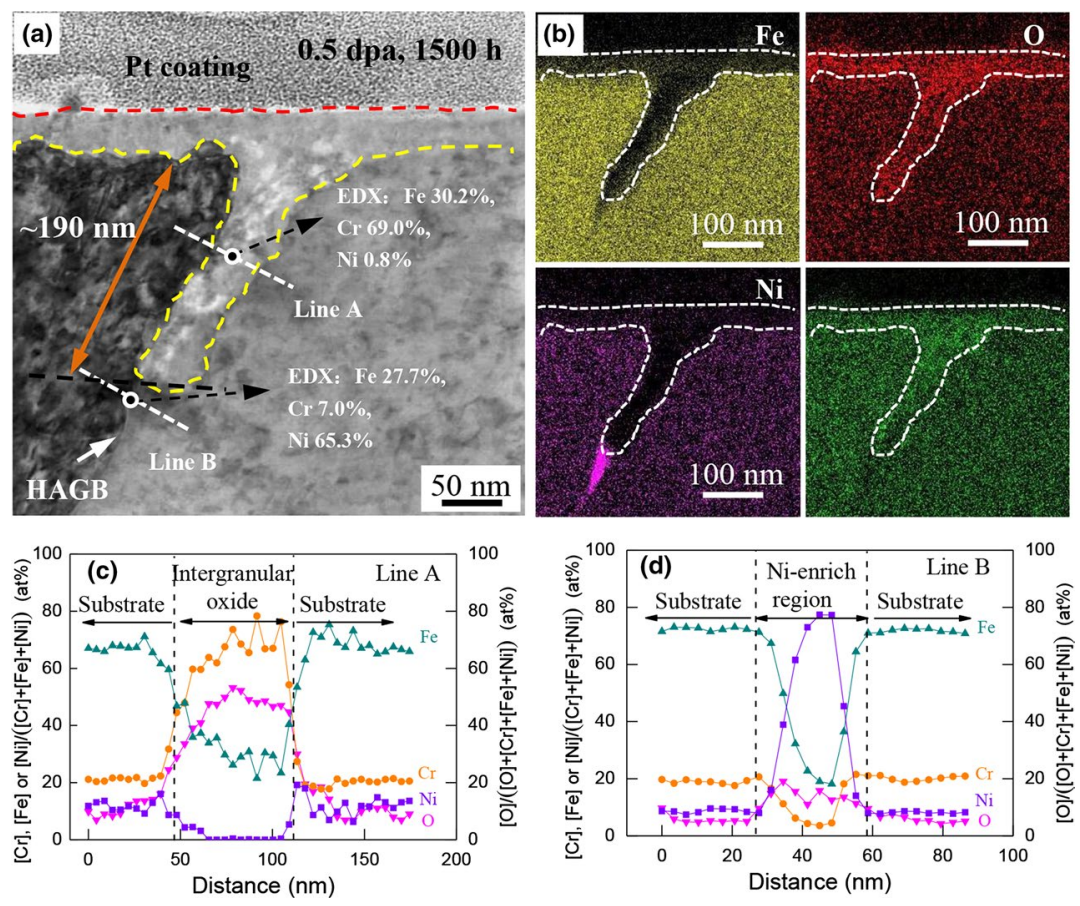

Fig. 9 a TEM observation of the cross section of a grain boundary on $0.5 \mathrm{dpa}$ irradiated specimen following the 1500-h exposure in PWR primary water at $320^{\circ} \mathrm{C}$. b The corresponding EDX mappings for O, Cr, Fe and Ni, respectively. $\mathbf{c}$ and $\mathbf{d}$ EDX point scans across the grain boundary collected along the red lines shown in a
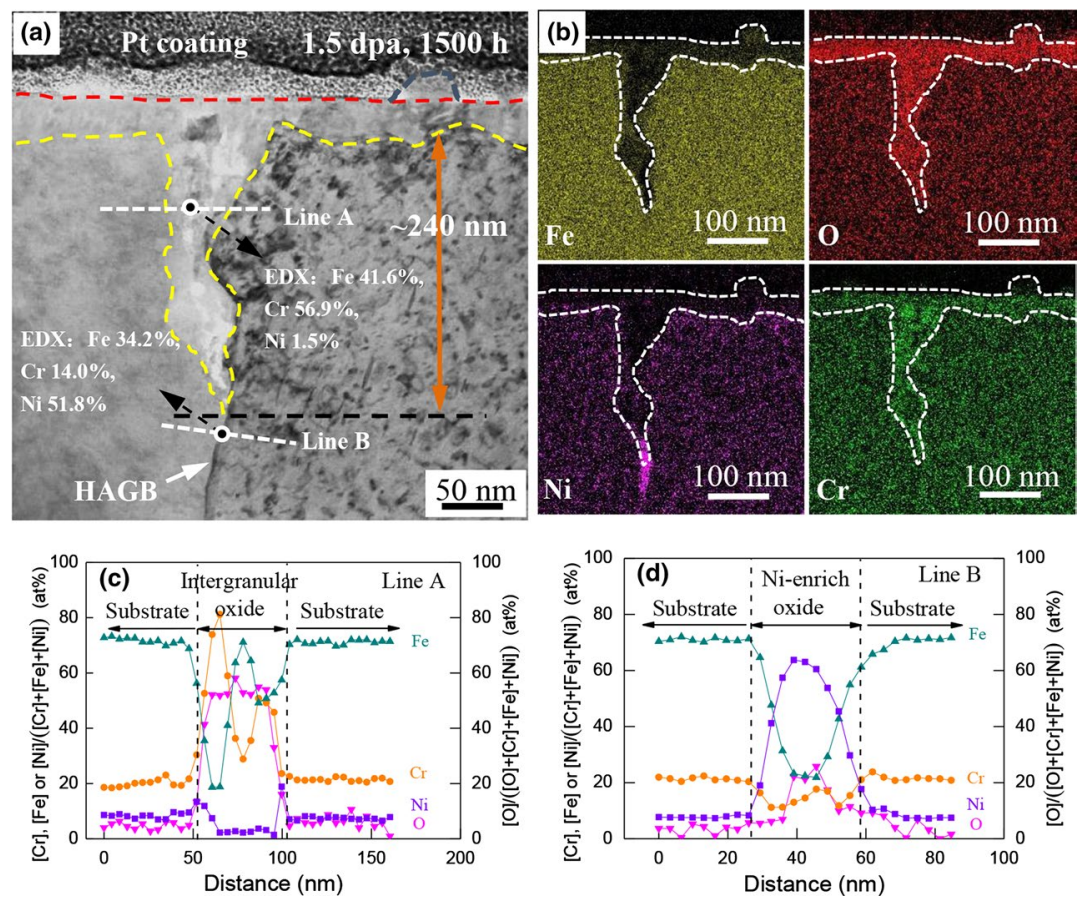

Fig. 10 a TEM observation of the cross section of a grain boundary on 1.5 dpa irradiated specimen following the 1500-h exposure in PWR primary water at $320^{\circ} \mathrm{C}$. b The corresponding EDX mappings for $\mathrm{O}, \mathrm{Cr}, \mathrm{Fe}$ and $\mathrm{Ni}$, respectively. $\mathbf{c}$ and $\mathbf{d}$ EDX point scans across the grain boundary collected along the red lines shown in $\mathbf{a}$ 


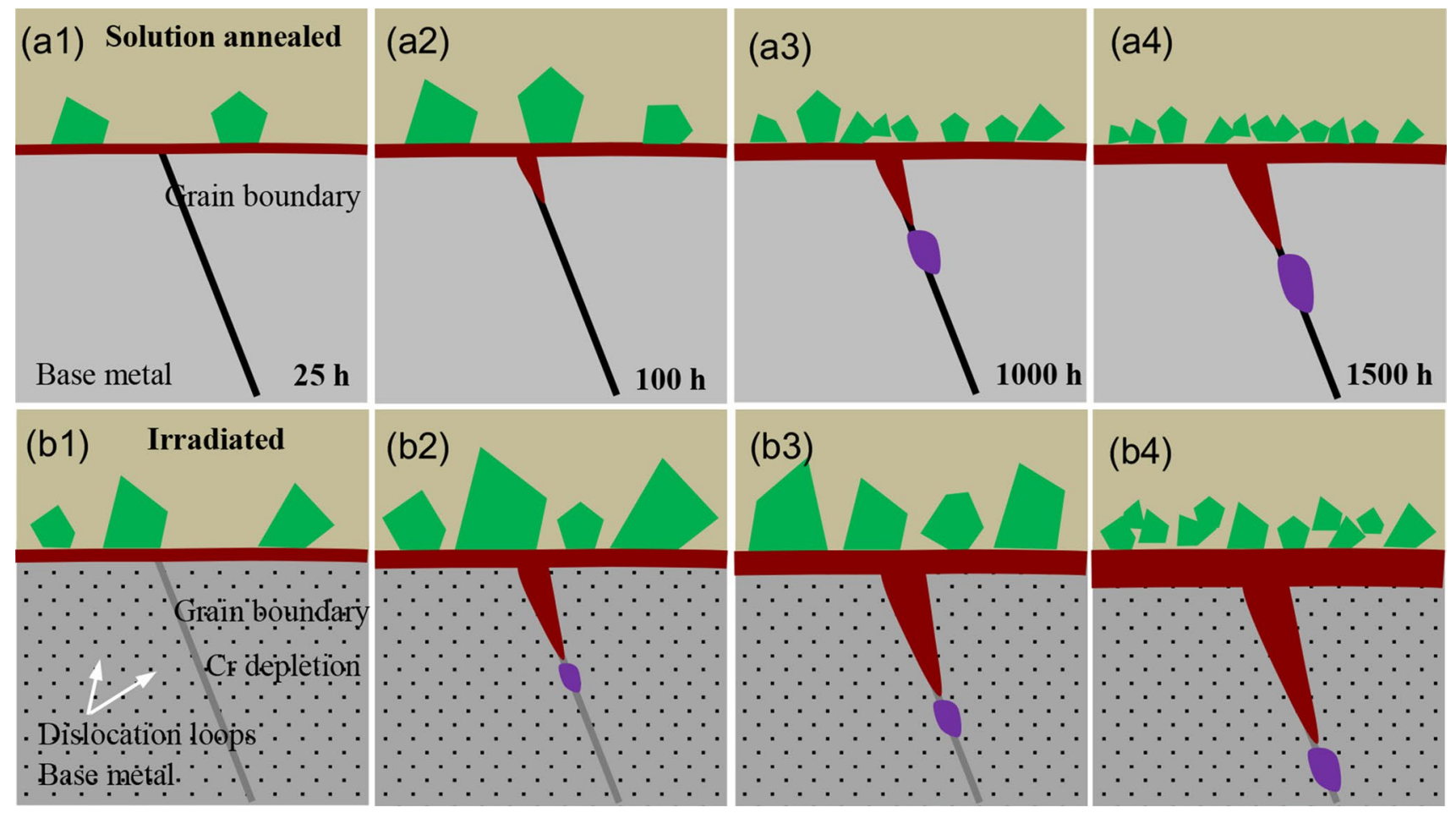

Fig. 11 Schematics showing the evolution of the oxide scale formed on a1-a4 solution-annealed and b1, b2 irradiated specimens of 304NG SS following the exposure to PWR primary water at $320^{\circ} \mathrm{C}$

cation site in the alloy, respectively, and $\mathrm{V}_{\mathrm{M}}^{\prime \prime}$ is metal vacancies $(\mathrm{M}=\mathrm{Fe}$ and $\mathrm{Cr})$.

Reaction (2) accounts for the consumption of $\mathrm{Cr}$ and $\mathrm{Fe}$ cations at the oxide/matrix interface, whereas reaction (3) describes the lattice-conservative process involving the counterdiffusion of metal vacancies. During the oxide growth, Ni reluctantly diffused to the oxide/matrix interface by the preferential oxidation of $\mathrm{Cr}$, where cation sites of $\mathrm{Fe}$ and $\mathrm{Cr}$ as well as the metal vacancies were consumed by the following reaction $[42,43]$ :

$\mathrm{Ni}_{\mathrm{Ni} \text { (oxide) }}^{\ddot{*}}+\mathrm{V}_{\mathrm{m}}^{\prime \prime} \leftrightarrow \mathrm{Ni}_{\mathrm{Ni}, \mathrm{Fe}}^{\times}+\mathrm{Ni}_{\mathrm{Ni}, \mathrm{Cr}}^{\times}$

where $\mathrm{Ni}_{\mathrm{Ni} \text { (oxide) }}$ represents $\mathrm{Ni}$ in oxide, $\mathrm{V}_{\mathrm{m}}^{\prime \prime}$ represents metal vacancies $(\mathrm{m}=\mathrm{Fe}$ and $\mathrm{Cr})$ and $\mathrm{Ni}_{\mathrm{Ni}, \mathrm{Fe}}^{\times}$and $\mathrm{Ni}_{\mathrm{Ni}, \mathrm{Cr}}^{\times}$represent $\mathrm{Ni}$ in cation site of $\mathrm{Fe}$ and $\mathrm{Cr}$ in the alloy. Consequently, a higher enrichment of $\mathrm{Ni}$ at the oxide/matrix interface suggested a larger amount of consumption of $\mathrm{V}_{\mathrm{M}}^{\prime \prime}$ and cation sites of $\mathrm{Fe}$ and $\mathrm{Cr}$. This could certainly mitigate $\mathrm{Fe}$ and $\mathrm{Cr}$ cations outward diffusion to the oxide/matrix interface and further decrease formation of oxygen vacancy in the oxide. As a result, the joint effect of a less protectability of the oxide itself and a higher diffusion rate of $\mathrm{Fe}$ and $\mathrm{Cr}$ cations to the oxide/matrix interface accounts for the higher intergranular corrosion rate on the $1.5 \mathrm{dpa}$ irradiated specimen.

\section{Conclusions}

This work studied the corrosion behavior and mechanism of proton-irradiated 304 nuclear grade stainless steel in hightemperature water. Conclusions can be drawn as follows:

1. Increasing the irradiation dose results in an evolution of the outer layer consisting of oxide particles. Large oxide particles with a lower packing density were formed in the short exposure period of $\leq 500 \mathrm{~h}$, while small oxide particles with a higher packing density were formed by increasing the exposure period to $1000-1500 \mathrm{~h}$.

2. Thickness of the inner oxide film followed a power law, while the corrosion rate constant increased with increasing irradiation dose.

3. Increasing irradiation dose decreases the $\mathrm{Cr}$ content of intergranular oxide in the steel in PWR primary water, in addition to the $\mathrm{Ni}$ enrichment adjacent to the oxide.

4. The Ni enrichment adjacent to the oxide mitigates the intergranular corrosion by decreasing the diffusion of ions at the oxide/matrix interface.

Acknowledgements This work was financially supported by the International Science \& Technology Cooperation Program of China (No. 2014DFA50800) and partly supported by the Essential Research Fund 
by SNPTC (No. 2015SN010-007). The authors gratefully acknowledge the Michigan Ion Beam Laboratory at the University of Michigan for performing proton implantation experiments.

\section{References}

[1] K.J. Stephenson, G.S. Was, J. Nucl. Mater. 444, 331 (2014)

[2] H. Nishioka, K. Fukuya, K. Fujii, T. Torimaru, J. Nucl. Sci. Technol. 45, 1072 (2008)

[3] Y. Chen, B. Alexandreanu, W.K. Soppet, W.J. Shack, K. Natesan, A.S. Rao, Slow strain rate tensile tests of irradiated austenitic stainless steels in simulated PWR environment. Paper presented at the 15th international conference on environmental degradation of materials in nuclear power systems-water reactors, Colorado, 1277 (2011)

[4] Z. Jiao, G.S. Was, J.T. Busby, The role of localized deformation in iascc of proton-irradiated austenitic stainless steels. Paper presented at the 13th international conference on environmental degradation of materials in nuclear power systems, Whistler, British Columbia, 19 (2007)

[5] Z. Jiao, G.S. Was, T. Miura, K. Fukuya, J. Nucl. Mater. 452, 328 (2014)

[6] Z. Jiao, G.S. Was, J. Nucl. Mater. 408, 246 (2011)

[7] Z. Jiao, G.S. Was, J. Nucl. Mater. 407, 34 (2010)

[8] Z. Jiao, G.S. Was, J. Nucl. Mater. 382, 203 (2008)

[9] K. Fukuya, H. Nishioka, K. Fujii, T. Miura, T. Torimaru, J. Nucl. Mater. 417, 958 (2011)

[10] T. Miura, K. Fujii, K. Fukuya, Y. Ito, J. Nucl. Mater. 386-388, 210 (2009)

[11] K. Fukuya, H. Nishioka, K. Fujii, T. Miura, Y. Kitsunai, J. Nucl. Mater. 432, 67 (2013)

[12] M.D. McMurtrey, G.S. Was, Role of slip behavior in the irradiation assisted stress corrosion cracking in austenitic steels. Paper presented at the 15th international symposium on environmental degradation of materials in nuclear power systems-water reactors, Colorado, 1383 (2011)

[13] I. Ioka, Y. Ishijima, K. Usami, N. Sakuraba, Y. Kato, K. Kiuchi, J. Nucl. Mater. 417, 887 (2011)

[14] Z.C. Zheng, Y.X. Yu, W.P. Zhang, Z.Y. Shen, F.F. Luo, L.P. Guo, Y.Y. Ren, R. Tang, Acta Metall. Sin.-Engl. Lett. 30, 89 (2017)

[15] A.B. Du, W. Feng, H.L Ma, T. Liang, D.Q. Yuan, P. Fan, Q.L. Zhang, C. Huang, Acta Metall. Sin.-Engl. Lett. 30, 1049 (2017)

[16] P. Deng, C. Sun, Q.J. Peng, E.H. Han, W. Ke, Z. Jiao, Acta Metall. Sin. 55, 349 (2019)

[17] A. Turnbull, K. Mingard, J.D. Lord, B. Roebuck, D.R. Tice, K.J. Mottershead, N.D. Fairweather, A.K. Bradbury, Corros. Sci. 53, $3398(2011)$
[18] G.S. Was, Recent Developments in understanding irradiation assisted stress corrosion cracking. Paper presented at the 11th international symposium on environmental degradation of materials in nuclear power systems-water reactors, Washington, 965 (2003)

[19] P. Deng, Q.J. Peng, E.H. Han, W. Ke, C. Sun, Z. Jiao, Corros. Sci. 127, 91 (2017)

[20] S. Perrin, L. Marchetti, C. Duhamel, M. Sennour, F. Jomard, Oxid. Met. 80, 623 (2013)

[21] M. Dumerval, S. Perrin, L. Marchetti, M. Sennour, F. Jomard, S. Vaubaillon, Y. Wouters, Corros. Sci. 107, 1 (2016)

[22] C.S. Liu, J.Q. Wang, Z.M. Zhang, E.H. Han, W. Liu, D. Liang, Z.T. Yang, Sin Acta Metall. Sin.-Engl. Lett. 32, 506 (2019)

[23] P. Deng, Q.J. Peng, E.H. Han, W. Ke, C. Sun, H.H. Xia, Z. Jiao, Acta Metall. Sin. 53, 1588 (2017)

[24] Z. Jiao, G.S. Was, Acta Mater. 59, 1220 (2011)

[25] P. Ampornrat, Y.B. Chen, L.M. Wang, G.S. Was, Microstructure and oxidation mechanisms of ferritic-martensitic alloy HCM12A in supercritical water. Paper presented at the 14th international symposium on environmental degradation of materials in nuclear power systems-water reactors, Virginia Beach, 1751 (2009)

[26] Y.L. Han, E.H. Han, Q.J. Peng, W. Ke, Corros. Sci. 121, 1 (2017)

[27] X. Gao, X. Wu, Z.E. Zhang, H. Guan, E.H. Han, J. Supercrit. Fluids 42, 157 (2007)

[28] F. Huang, J.Q. Wang, E.H. Han, W. Ke, Corros. Sci. 76, 52 (2013)

[29] W.J. Kuang, X. Wu, E.H. Han, Corros. Sci. 52, 4081 (2010)

[30] W.J. Kuang, E.H. Han, X. Wu, J. Rao, Corros. Sci. 52, 3654 (2010)

[31] Y.J. Kim, Corrosion 51, 849 (1995)

[32] J. Robertson, Corros. Sci. 29, 1275 (1989)

[33] J. Robertson, Corros. Sci. 32, 443 (1991)

[34] R.J. Lemire, G.A. McRae, J. Nucl. Mater. 294, 141 (2001)

[35] P. Deng, Q.J. Peng, E.H. Han, W. Ke, Corrosion 73, 1237 (2017)

[36] S. Lozano-Perez, D.W. Saxey, T. Yamada, T. Terachi, Scr. Mater. 62, 855 (2010)

[37] K. Kruska, S. Lozano-Perez, D.W. Saxey, T. Terachi, T. Yamada, T. Smith, D.W. George, Corros. Sci. 63, 225 (2012)

[38] W.J. Kuang, G.S. Was, Acta Mater. 182, 120 (2020)

[39] C. Ma, E.H. Han, Q.J. Peng, W. Ke, Appl. Surf. Sci. 442, 423 (2018)

[40] Y.L. Han, J.N. Mei, Q.J. Peng, E.H. Han, W. Ke, Corros. Sci. 98, $72(2015)$

[41] S. Ghosh, M.K. Kumar, V. Kain, Appl. Surf. Sci. 264, 312 (2013)

[42] D.D. Macdonald, M.U. Macdonald, J. Electrochem. Soc. 137, 2395 (1990)

[43] L. Marchetti, S. Perrin, F. Jambon, M. Pijolat, Corros. Sci. 102, 24 (2016) 